Mens

Revue d'histoire intellectuelle et culturelle

mens

\title{
Charles-Philippe Courtois et Julie Guyot (dir.). La culture des patriotes, Québec, Éditions du Septentrion, 2012, 231 p.
}

\section{Marilyn Randall}

Volume 14, numéro 1, automne 2013

URI : https://id.erudit.org/iderudit/1032629ar

DOI : https://doi.org/10.7202/1032629ar

Aller au sommaire du numéro

Éditeur(s)

Centre de recherche en civilisation canadienne-française

ISSN

1492-8647 (imprimé)

1927-9299 (numérique)

Découvrir la revue

Citer ce compte rendu

Randall, M. (2013). Compte rendu de [Charles-Philippe Courtois et Julie Guyot (dir.). La culture des patriotes, Québec, Éditions du Septentrion, 2012, 231 p.]

Mens, 14(1), 156-159. https://doi.org/10.7202/1032629ar d'utilisation que vous pouvez consulter en ligne.

https://apropos.erudit.org/fr/usagers/politique-dutilisation/ 
secrétaire de la Province à agir sur l'éducation et la culture alors qu'aucun ministère ne leur était attribué.

- Marie-Thérèse Lefebvre Université de Montréal

\section{Charles-Philippe Courtois et Julie Guyot (dir.). La culture despatriotes, Québec, Éditions du Septentrion, 2012, 231 p.}

Les historiens n'ont cessé de trouver dans les rébellions du BasCanada une source inépuisable de matière à réflexion et, ce faisant, n'ont pas non plus hésité à tirer dans tous les sens possibles les causes et les effets, les pour et les contre, les explications et les contreexplications. Qu'il s'agisse de fournir une leçon d'obéissance civile ou un modèle de révolution, les rébellions conviennent à tous les usages et, en dépit d'une longue tradition historiographique, font toujours figure d'énigme à éclaircir. Si les rébellions se prêtent si facilement à des interprétations différentes par des générations successives d'historiens, c'est qu'elles ne sauraient se réduire à un seul événement et que "les patriotes " sont loin de former un groupe homogène. Ses diverses interprétations n'éclairent pas seulement les enjeux de la période historique, mais permettent aussi de tracer l'histoire des idéologies au Québec (et au Canada).

C'est à l'intitulé de la "Bibliographie sélective " de l'ouvrage que l'on découvre le véritable sujet des essais réunis par CharlesPhilippe Courtois et Julie Guyot. La culture des patriotes traite, en effet, plus particulièrement $\mathrm{du}$ " républicanisme et de la culture politique du mouvement patriote» (p. 219). Cela dit, quelques essais s'efforcent d'étendre le sens de cette expression de façon à inclure la culture qu'ont léguée les patriotes au Québec contemporain, non seulement du point de vue politique, mais aussi dans les créations littéraires et cinématographiques. Comme le disent Lucille Beaudry et Marc Chevrier dans leur survol éclairant de l'historiographie des rébellions, celle-ci ne nous renvoie pas qu'aux idées politiques de l'époque, "mais aussi et surtout à l'historiographie qui nous est 
accessible à leur sujet et à leurs appropriations en œuvres artistiques ou commémorations populaires»(p. 84).

Ainsi, les historiens qui signent les essais dans le présent volume se rallient à la plus récente tendance dans l'analyse des rébellions, laquelle consiste à souligner leur inspiration républicaine. L'ouvrage sonde deux questions en particulier : premièrement, quelles étaient les sources de la culture politique républicaine des patriotes et, ensuite, comment ces influences se sont-elles implantées au Québec? Tous s'accordent sur certaines grandes lignes : les sources étaient nombreuses et parfois contradictoires; et les patriotes se plaçaient volontiers dans un contexte de référence aux courants idéologiques " atlantiques", tant anciens que modernes, européens qu'américains. Le mouvement est ainsi marqué par sa diversité, non seulement dans ses fondements idéologiques, mais aussi du point de vue des intérêts et des « enjeux locaux » que Papineau, malgré ses tentatives, n’arrivait pas à réconcilier, comme l'explique Gilles Laporte. Selon Courtois, « définir le dessein des Patriotes, la place respective accordée à la nation et à la république, paraît difficile" (p. 112), tant ils adhéraient à des objectifs contradictoires et entremêlés entre pancanadianisme, annexionnisme et nationalisme. Mais l'apparence d'une diversité irréconciliable ne serait que l'effet de l'application d'une antithèse « erronée » qui veut opposer chez les patriotes « un nationalisme conservateur et un républicanisme sans aucun fondement national» (p. 118). Le point commun qui permettrait de lier tous les éléments du mouvement serait l'option indépendantiste (p. 117).

Pour sa part, Stéphane Kelly résume bien les trois courants idéologiques dominants dans les années 1830 : le conservateur, représenté par les commerçants britanniques; le républicain, qui réunissait Papineau, O'Callaghan et W. Nelson; et, entre les deux, le libéral, qui sortit dominant à la suite de l'Acte d'Union, représenté par John Neilson, Étienne Parent et Louis-Hippolyte La Fontaine. Si ces deux derniers groupes ont pu trouver des points de ralliement, c'est à la suite de l'Union qu'ils vont se diviser et laisser la place aux conservateurs. Cette période est analysée par Éric Bédard, qui défend 
la posture réformiste comme étant la seule option valable dans la conjoncture post-Union.

Les sources de la pensée républicaine des patriotes sont nécessairement internationales, puisant dans le fonds antique, la philosophie des Lumières et celles des révolutions américaine et française. Or, si ces idées nourrissent le programme des patriotes, c'est surtout grâce à leurs interprètes canadiens. Plusieurs essais insistent sur les origines antiques du républicanisme des patriotes : Louis-George Harvey, Marc-André Bernier, Marc Chevrier et Stéphane Kelly se penchent sur différents aspects de cette influence et ensemble ils fournissent non seulement une leçon de politique canadienne, mais ils éclairent aussi l'importance des sources gréco-romaines dans la pensée républicaine internationale. L'essai de Chevrier sur l'importance des Politiques d'Aristote dans la pensée de Papineau éclaire les sensibilités philosophiques du " grand homme " ainsi que l'influence de la pensée aristotélicienne sur la réflexion républicaine en général.

La postface de Marc-André Bernier fait, pour sa part, le pont entre la culture antique et celle des patriotes en situant l'inspiration antique de Pierre-Stanislas Bédard et en soulignant l'importance de la notion des " temps parallèles ", ancien et moderne, qui animait la culture des patriotes. Dans son essai sur Bédard, Gilles Gallichan nous a déjà rappelé l'importance de ce père canadien des idéaux patriotes : fondateur du journal Le Canadien et leader du Parti canadien, ce " philosophe " imbu d'une érudition à la fois antique et contemporaine aurait " jeté les bases politiques desquelles sortiront plusieurs tendances [...] au cours des décennies suivantes" (p. 57). Et si les révolutions américaine et française occupent une place importante dans la culture patriote, c'est grâce aux " disséminateurs " canadiens de ces philosophies politiques, tel que l'établit Bernard Andrès. À l'image de plusieurs autres contributeurs du volume, Andrès ne manque pas de rappeler la pertinence de l'héritage des patriotes pour le Québec contemporain et va jusqu’à montrer en quoi il interroge encore nos débats identitaires : "Jusqu' où peut-on transiger avec le principe d'égalité des hommes et des femmes et avec le principe 
de la neutralité religieuse de l'État? [...] Souhaitons, enfin, que le gouvernement actuel n'oublie pas le tribut que nous devons à ces pionniers de la pensée républicaine" (p. 42).

L'ensemble des essais contenus dans cet ouvrage affiche un souci métahistorique et fournit d'importantes informations sur l'évolution de l'historiographie canadienne relative aux rébellions. Si l'essai de Beaudry et Chevrier se penche plus particulièrement sur les processus "d'appropriation et d'occultation " de la culture politique des patriotes, toutes les contributions foisonnent de références à l'historiographie, tant moderne que plus ancienne. La polémique n'est pas absente dans la mesure où des historiens contemporains sont mis sur la sellette, et l'article d'Éric Bédard sur les Réformistes se veut une réplique directe aux critiques subies par son ouvrage Les Réformistes: une génération canadienne-française au milieu du XIX siècle (Éditions du Boréal, 2009).

L'ouvrage est éclairant, bien documenté et érudit. Il s'adresse toutefois à un lectorat initié à la période et exige une connaissance approfondie des enjeux et des interprétations des rébellions. En même temps, les références bibliographiques qui accompagnent les articles individuels fournissent une introduction exhaustive aux ouvrages sur le sujet. Par ailleurs, si la contribution de Beaudry et Chevrier est surtout riche quant au legs historiographique et populaire des rébellions, aucun des essais ne manque de signaler le contexte dans lequel il se situe ou, plus fréquemment, qu'il conteste. En substance, l'ouvrage apporte une contribution importante à la tradition historiographique des rébellions, et les directeurs espèrent qu'il ouvrira « de nouvelles pistes de recherche en histoire intellectuelle, politique et culturelle du XIx ${ }^{\mathrm{e}}$ siècle québécois» (p. 24). Tout porte à croire qu'effectivement La culture des patriotes n'aura pas le dernier mot sur ce sujet.

- Marilyn Randall 